Research Article

\title{
Citral Induced Apoptosis through Modulation of Key Genes Involved in Fatty Acid Biosynthesis in Human Prostate Cancer Cells: In Silico and In Vitro Study
}

\author{
Sri Renukadevi Balusamy ${ }^{D},{ }^{1}$ Haribalan Perumalsamy $\left(D,{ }^{2}\right.$ Karpagam Veerappan, \\ Md. Amdadul Huq, ${ }^{3}$ S. Rajeshkumar $\mathbb{D}^{4}{ }^{4}$ T. Lakshmi, ${ }^{4}$ and Yeon Ju Kim $\mathbb{D}^{2}$ \\ ${ }^{1}$ Department of Food Science and Biotechnology, Sejong University, Gwangiin-gu, Seoul, Republic of Korea \\ ${ }^{2}$ Graduate School of Biotechnology, College of Life Science, Kyung Hee University, Yongin 446-701, Republic of Korea \\ ${ }^{3}$ Department of Food Nutrition, Chung Ang University, Anseong-si, Gyeonggi-do 17546, Republic of Korea \\ ${ }^{4}$ Department of Pharmacology, Saveetha Dental College and Hospitals, Saveetha University, SIMATS, \\ Chennai 600077, TN, India
}

Correspondence should be addressed to Sri Renukadevi Balusamy; renucoimbatore@gmail.com, Haribalan Perumalsamy; harijai2004@gmail.com, and Yeon Ju Kim; yeonjukim@khu.ac.kr

Received 29 April 2019; Revised 31 August 2019; Accepted 21 November 2019; Published 18 March 2020

Academic Editor: Paul W. Doetsch

Copyright (C) 2020 Sri Renukadevi Balusamy et al. This is an open access article distributed under the Creative Commons Attribution License, which permits unrestricted use, distribution, and reproduction in any medium, provided the original work is properly cited.

\begin{abstract}
The isomers of citral (cis-citral and trans-citral) were isolated from the Cymbopogon citratus (DC.) Stapf oil demonstrates many therapeutic properties including anticancer properties. However, the effects of citral on suppressing human prostate cancer and its underlying molecular mechanism have yet to be elucidated. The citral was isolated from lemongrass oil using various spectroscopic analyses, such as electron ionized mass spectrometry (EI-MS) and nuclear magnetic resonance (NMR) spectroscopy respectively. We carried out 3-(4,5-dimethylthiazol-2-yl)-2,5-diphenyl tetrazolium bromide (MTT) assay to evaluate the cell viability of citral in prostate cancer cells (PC-3 and PC3M). Furthermore, to confirm that PC3 undergoes apoptosis by inhibiting lipogenesis, we used several detection methods including flow cytometry, DNA fragmentation, Hoechst staining, PI staining, oil staining, qPCR, and Western blotting. Citral impaired the clonogenic property of the cancer cells and altered the morphology of cancer cells. Molecular interaction studies and the PASS biological program predicted that citral isomers tend to interact with proteins involved in lipogenesis and the apoptosis pathway. Furthermore, citral suppressed lipogenesis of prostate cancer cells through the activation of AMPK phosphorylation and downregulation of fatty acid synthase (FASN), acetyl coA carboxylase (ACC), 3-hydroxy-3-methylglutaryl-coenzyme A reductase (HMGR), and sterol regulatory element-binding protein (SREBP1) and apoptosis of PC3 cells by upregulating $B A X$ and downregulating $\mathrm{Bcl}-2$ expression. In addition, in silico studies such as ADMET predicted that citral can be used as a safe potent drug for the treatment of prostate cancer. Our results indicate that citral may serve as a potential candidate against human prostate cancer and warrants in vivo studies.
\end{abstract}

\section{Introduction}

Prostate cancer is the second most leading cancer in Western countries [1]. However, the prevalence of prostate cancer in Asian countries are lower and considered to be the fifth most common cancer among Korean men population [2]. In recent years, the incidence of prostate cancer in Korea is rapidly increasing. According to the Korean National
Cancer Incidence Database, the age-standardized incidence report suggests that the annual percent change in prostate cancer was $11.4 \%$ which is the second-largest cancer observed following the thyroid cancer [3]. A decrease in the mortality rate of prostate cancer patients may be attributed to early diagnosis. Current therapeutic measures fail to cure the malignancy and life span can be extended only for 4-6 months denoting that chemoprevention of prostate cancer 
is the main approach to reduce the morbidity [4]. Therefore, identifying the novel drug from natural products can be the most effective and alternative therapy to reduce the mortality of prostate cancer. Thus, the researchers are highly focusing on natural products for the prevention of many cancers.

There is an increasing evidence that metabolic reprogramming plays a significant role in the development of cancer and disease progression [5]. An increase in fatty acid metabolism is linked to altered cancer cell metabolism. There are several studies conducted to prove the link between fatty acid synthesis and cancer progression including prostate cancer [6], pancreatic cancer [7], hepatocellular carcinoma [8], and breast cancer [9]. Therefore, identifying the target that inhibits the genes and enzymes involved in fatty acid synthesis can reduce the growth of the tumor cells and increase the life span of a cancer patient.

Cymbopogon citratus (DC.) Stapf. commonly known as lemongrass is extensively used as a medicinal plant in folk medicine for the treatment of various diseases as it has antimutagenic, antiproliferative, and antiparasitic properties. By the process of steam distillation, a volatile oil is obtained from the leaves of lemongrass. The pharmacological properties of lemongrass were due to the presence of citral which is an acyclic monoterpene. Many studies reported that lemongrass oil possesses many pharmacological properties such as antimicrobial [10] and insecticidal [11]properties; only few studies demonstrated the anticancer properties of lemongrass, for instance, cervical cancer, HeLa and ME-180 cells [12], breast cancer (MCF-7) cells [13], prostate cancer, PC3, and LNCap [14]. However, to date its molecular mechanism in prostate cancer cells has not been elucidated. Our present study isolated citral from C. citratus combined both in silico and in vitro analyses to reveal the potential antiproliferative activity of citral as a possible candidate to induce apoptosis by targeting lipogenesis pathway.

\section{Materials and Methods}

2.1. Instrumental Analysis. The ${ }^{1} \mathrm{H}$ and ${ }^{13} \mathrm{C}$ NMR spectra were recorded in DMSO on an AVANCE 600 spectrometer (Bruker, Rheinstetten, Germany) at 600 and $150 \mathrm{MHz}$, respectively, using tetramethylsilane as an internal standard. The chemical shifts are given in $\delta(\mathrm{ppm})$. The DEPT spectra were acquired using the Bruker software. The UV spectra were obtained in ethanol or methanol on a UVICON 933/ 934 spectrophotometer (Kontron, Milan, Italy) and the mass spectra on a JMS-DX 303 spectrometer (Jeol, Tokyo, Japan). Silica gel 60 (0.063-0.2 mm) (Merck, Darmstadt, Germany) was used for column chromatography. Merck precoated silica gel plates (Kieselgel 60F 254) were used for analytical thin-layer chromatography (TLC). An Isolera one mediumpressure liquid chromatograph (Biotage, Uppsala, Sweden) and an Agilent 1200 high-performance liquid chromatograph (Agilent, Santa Clara, CA, USA) were used to isolate the active compounds.
2.2. Materials. Commercially available anticancer agent cisplatin and 3-(4,5-dimethylthiazol-2-yl)-2,5-diphenyl tetrazolium bromide (MTT) were purchased from SigmaAldrich (St. Louis, MO). Rosewell Park Memorial Institute (RPMI) 1640 medium, Dulbecco's Modified Eagle's Medium (DMEM), and Fetal Bovine Serum (FBS) were supplied by Life Technologies (Grand Island, NY). Phosphate-buffered saline (PBS) was purchased from Sigma-Aldrich. Antibiotic-antimycotic solution and 0.5\% trypsin-ethylenediaminetetraacetic acid (EDTA) were purchased from Invitrogen (Grand Island, NY, USA). Maxima SYBR Green/ROX qRT-PCR Master Mix was supplied by Thermo Scientific (Foster, CA, USA). All the other chemicals and reagents used in this study were reagent-grade quality and available commercially.

2.3. Antibodies. The primary antibodies used in this study were anti- $\beta$ actin antibody (sc-47778), anti-BAX rabbit polyclonal antibody (sc-493), Bcl-2 rabbit polyclonal antibody (sc-492), AMPKa1 (sc-398861), ACC (sc-137104), fatty acid synthase antibody (sc-55580), SREBP1 (sc-13551), and HMGCR (sc-271595), and the secondary antibodies used in this study were goat anti-rabbit immunoglobulin $\mathrm{G}(\mathrm{IgG}) \mathrm{H}$ \& amp, L (HRP) (sc-2054), goat anti-mouse IgG-HRP (sc2005), and mouse anti-rabbit IgG-HRP (sc-2357). All the above antibodies were purchased from Santa Cruz Biotechnology (Dallas, TX, USA).

\subsection{Medium-Pressure Liquid Chromatography (MPLC).} The lemongrass oil $(5 \mathrm{~g})$ was monitored by TLC on silica gel plates (Silica gel $60 \mathrm{~F}_{254}$ ) developed with hexane and ethyl acetate solvent system as previously described [15]. Based on TLC pattern, it was separated by MPLC using a Biotage Isolera apparatus equipped with a UV detector at $254 \mathrm{~nm}$ and $365 \mathrm{~nm}$ and a column cartridge SNAP (100 g silica gel) with column volume $132 \mathrm{~mL}$. Separation was achieved with a gradient of hexane and ethyl acetate $(100: 0 \quad(264 \mathrm{~mL}), 9: 1 \quad(396 \mathrm{~mL}), 8: 2 \quad(396 \mathrm{~mL}), 7: 3$ $(660 \mathrm{~mL}), 6: 4(264 \mathrm{~mL}), 5: 5(264 \mathrm{~mL}), 3: 7(264 \mathrm{~mL})$, and $1: 9(132 \mathrm{~mL})$, by volume) at a flow rate $25 \mathrm{~mL} / \mathrm{min}$ to provide 105 fractions (each about $22 \mathrm{~mL}$ ). Column fractions were monitored by TLC on silica gel plates (Silica gel $60 \mathrm{~F}_{254}$ ) developed with hexane and ethyl acetate ( $8: 2$ by volume) mobile phase. Fractions with similar $R_{\mathrm{f}}$ values on the TLC plates were pooled. Spots were detected by spraying with $5 \%$ sulfuric acid and then heating on a hot plate as stated previously. A preparative high-performance liquid chromatography (HPLC) was performed to separate the constituents from active fractions. The column was a $7.8 \mathrm{~mm}$ i.d. $\times 300 \mathrm{~mm}$ $\mu$ Bondapak C18 (Waters, Milford, MA, USA) with a mobile phase of methanol and water ( $85: 15$ by volume) at a flow rate of $1 \mathrm{~mL} \cdot \mathrm{min}^{-1}$. Chromatographic separation was monitored using a UV detector at $233 \mathrm{~nm}$. Finally, an active constituent 1 (citral) $(28 \mathrm{mg})$ was isolated at a retention time of $13.8 \mathrm{~min}$. 
2.5. Prediction of Pharmacokinetic and Biological Activity. The pharmacokinetic (ADMET: absorption, distribution, metabolism, excretion, and toxicity) and drug-likeness (Lipinski rule of five) properties were calculated for neral and geranial molecules using SwissADME [16] and PreADMET web servers [17]. The ADMET properties such as human intestinal absorption (HIA), plasma protein binding ability (PPB), blood-brain barrier (BBB), and toxicity were predicted for cis-neral and trans-geraniol drug efficiencies. In addition, drug-likeness activities were predicted based on Lipinski's rule. Further, prediction of activity spectra for substances (PASS) web server was used for predicting putative biological activity [18] based on cis-neral and transgereniol chemical structures. This program resulted in a list of putative biological activities with a chance of probability scores [19]. The pharmacokinetic properties, drug-likeness, and biological activity were calculated based on SMILES (simplified molecular-input line-entry system) of chemical structures.

2.6. Molecular Interaction Studies. The three-dimensional crystal structures of B-cell lymphoma 2 (Bcl-2) and fatty acid synthase (FASN) were used for docking simulations with neral and geranial molecules. Bcl-2 (PDB ID: 4LVT) [20] with navitoclax and FASN (PDB ID: 2PX6) with orlistat [21] were downloaded from RCSB protein databank. For docking simulations, atomic coordinates were separated from complex structure, hydrogen atoms were added, and all water molecules were removed. Further, known inhibitor molecules were used as positive controls and their interaction sites were considered as the most favorable regions for docking reproducibility [22]. In case of ligands, their chemical structure was drawn using ChemSketch program and later was converted into a three-dimensional (3D) structure by using Discovery Studio Visualizer (DS, V17.2.0) (DS, http://www.accelrys.com; Accelrys, Inc. San Diego, CA, USA). The AutoDock Vina [23] program was implemented to find out the molecular level interactions, and the results were visualized by using DS. The detailed protein, ligand preparation, and docking parameters were described previously [24].

2.7. Cell Lines and Culture Conditions. Two human prostate cancer cell lines used in this study were as follows: PC3, human prostate cancer cell line; and PC3M, metastaticderived variant of human prostate cancer cell line; they were purchased from the American Type Culture Collection (ATCC) (Manassas, VA, USA). One human lung normal cell MRC-5 (human fetal lung fibroblast cell line) was purchased from the Korean Cell Line Bank (Seoul, South Korea). All cell lines were cultured with RPMI 1640 or DMEM containing $10 \%$ FBS and $1 \%$ antibiotic-antimycotic solution under $5 \% \mathrm{CO}_{2}$ at $37^{\circ} \mathrm{C}$.

2.8. Cell Viability Assay. The cell cytotoxicity of citral toward the human prostate cancer cells (PC3 and PC-3M) was evaluated using an MTT assay performed as described previously $[25,26] .10 x$ MTT stock solution $(5 \mathrm{mg} / \mathrm{mL})$ was dissolved in phosphate-buffered saline (PBS) ( $\mathrm{pH} 7.4)$, filter sterilized, and stored at $-20^{\circ} \mathrm{C}$. We used $2 \times 10^{4}$ cells per well (96-well plates) containing $100 \mu \mathrm{l}$ of the complete culture medium. After $24 \mathrm{~h}$, the citral test samples of different concentrations were added onto 96-well plates. The final concentration of DMSO Hybri-Max in all assays was less than $0.1 \%$. Based on the preliminary test results, the antiproliferative activity of citral for PC3 was treated with 0,5 , $10,15,25,50,100 \mu \mathrm{g} / \mathrm{ml}$ concentration whereas, for PC $3 \mathrm{M}$ cells, citral was treated with $0,3.75,7.5,12.5,25,50,100 \mu \mathrm{g} /$ $\mathrm{ml}$ concentrations, respectively. The culture plates were incubated for 2 days at $37^{\circ} \mathrm{C}$ supplied with humidified atmosphere of $5 \% \mathrm{CO}_{2}$. The plates were then washed with $100 \mu \mathrm{l}$ PBS and $0.05 \%$ of $100 \mu \mathrm{l}$ MTT reagent was added to each well and then incubated for $4 \mathrm{~h}$ as stated previously. MTT solution was removed and $200 \mu \mathrm{l}$ DMSO was added to each well. Finally, the plate was shaken in a microplate shaker for $10 \mathrm{~min}$ in dark condition to dissolve the purple formazan crystals. Cisplatin served as a positive control and was similarly formulated. The DMSO solution is used as a negative control. The optical density values were recorded using a VersaMax microplate reader (Molecular Devices, Sunnyvale, CA, USA) at $560 \mathrm{~nm}$ and $670 \mathrm{~nm}$, respectively. Blank values were subtracted from experimental values.

2.9. Light Microscopy. The PC 3 and PC-3M cell lines were cultured under the same conditions as those used for the cell maintenance. Cells were seeded into 96-well culture plates at a density of $2 \times 10^{4}$ cells per well and grown for overnight. The cells were treated with or without citral $(0,3.75,7.5,12.5$, $25,50,100 \mu \mathrm{g} / \mathrm{ml}$ ) in $0.1 \%$ DMSO for $48 \mathrm{~h}$. Cisplatin served as a reference control and was similarly prepared to that of citral. DMSO solution served as a negative solution. Two days after treatment, a morphological characteristic of treated and untreated cells was observed through a Leica DMIL LED equipped with an Integrated 5.0 Mega-Pixel MC 170 HD camera (Wetzlar, Germany).

2.10. Colony Forming Assay. $1 \times 10^{3}$ cells of PC-3 were seeded into 6-well sterile plates as described previously $[25,26]$. After adhesion, the cells were treated with different concentrations of citral ranging between,$(0,5,10,15,25,50$, $100 \mu \mathrm{g} / \mathrm{ml}$ ) respectively. Control wells were treated with only $0.1 \%$ DMSO. A day after incubation, the media were aspirated, and fresh media were added and incubated for 7 days at $37^{\circ} \mathrm{C}$ incubator supplied with $5 \% \mathrm{CO}_{2}$. The clones developed were fixed with glutaraldehyde, stained using crystal violet, counted, and graphically plotted. Experiments were performed in triplicate and statistical analyses were carried out using Student's $t$-test.

2.11. AnnexinV-FITC/PI Staining Assay. AnnexinV-FITC/PI staining was performed as described previously $[25,26]$, by following the protocol of the AnnexinV-FITC Apoptosis Detection Kit (BD Pharmingen, San Diego, CA, USA). In brief, PC-3M cells $\left(2 \times 10^{5} /\right.$ well $)$ were treated with different 
concentrations of citral (10 and $20 \mu \mathrm{g} / \mathrm{ml})$ for two days. Cells were harvested, washed twice with $1 \mathrm{~mL}$ cold PBS, and centrifuged at $300 \times \mathrm{g}$ for $5 \mathrm{~min}$. Later, cells were suspended in $100 \mu \mathrm{l}$ of binding buffer containing $5 \mu \mathrm{l}$ AnnexinV-FITC and $5 \mu \mathrm{l}$ PI staining solution. Cells were incubated at room temperature for 15 min under dark condition. At last, $400 \mu \mathrm{l}$ of binding buffer was added before the analysis by $\mathrm{BD}$ Biosciences FACS Aria II flow cytometer (San Jose, CA, USA). The data were analyzed using BD Biosciences FACSDiva software 2.13.

2.12. Hoechst Staining. Citral induced apoptosis was performed as described previously $[25,26]$ by Hoechst staining 33342 kits according to the manufacturer's instructions with slight modification. At first, cells were washed twice with PBS and fixed with $4 \%$ paraformaldehyde for $10 \mathrm{~min}$. Following that, cells were stained with $(10 \mu \mathrm{g} / \mathrm{ml})$ Hoechst staining solution at $37^{\circ} \mathrm{C}$ for $10 \mathrm{~min}$. The stained cells were washed 3 times with PBS, and imaging was captured under fluorescence microscope using a Leica DMLB fluorescence microscope (Wetzlar', Germany).

\subsection{Apoptotic Cell Propidium Iodide Staining.} $5 \times 10^{4} /$ well PC3 cells were seeded and apoptosis induction was measured as stated previously [26]. All wells except control wells were treated with $(10$ and $20 \mu \mathrm{g} / \mathrm{ml})$ of citral. The attached cells were then washed with $1 \mathrm{ml}$ PBS and fixed with $4 \%$ paraformaldehyde about 15 minutes. Later, fixed cells were washed with $1 \mathrm{ml}$ PBS and stained with $500 \mu \mathrm{l}$ propidium iodide (PI) $(5 \mu \mathrm{g} / \mathrm{mL})$ solution at room temperature for $10 \mathrm{~min}$. Apoptotic cells with condensed and fragmented nuclei were observed under fluorescence microscope using a Leica DMLB fluorescence microscope (Wetzlar, Germany).

2.14. Quantitative Real-Time Reverse Transcription-PCR Analysis. Treated and nontreated cultures of PC3 cell monolayers grown in $25 \mathrm{~cm}^{2}$ cell culture flasks (Corning Costar, NY, USA) were treated with $(5,10$ and $20 \mu \mathrm{g} / \mathrm{ml})$ of citral. After $48 \mathrm{~h}$ of treatments, the total RNA was extracted from nontreated and treated cultures using RNeasy Mini Kit (Qiagen, Hilden, Germany). For real-time quantitative PCR (qRT-PCR), $500 \mathrm{ng}$ of total RNA was reverse transcribed using oligo (dT)15 primer $(0.2 \mathrm{mM})$ and AMV Reverse Transcriptase $\left(10 \mathrm{U} \cdot \mu \mathrm{l}^{-1}\right)$, and cDNA was synthesized using superscript First-Strand Synthesis Kit (Invitrogen, Carlsbad, CA) according to the manufacturer's instructions. qRT-PCR was performed in 96-well plate using $100 \mathrm{ng}$ of cDNA in a $20 \mu$ reaction volume using SYBR ${ }^{\circledR}$ Green Sensimix Plus Master Mix (Quantace, Watford, England). Gene-specific primers used in this study were listed in Table 1 . The melting point analysis of PCR products was carried out, which resulted in a single peak, indicating the presence of a single PCR product amplification. The thermal cycler conditions recommended by the manufacturer were used as follows: $10 \mathrm{~min}$ at $95^{\circ} \mathrm{C}$, followed 40 cycles of $95^{\circ} \mathrm{C}$ for $10 \mathrm{~s}, 58^{\circ} \mathrm{C}$ for $10 \mathrm{~s}$, and $72^{\circ} \mathrm{C}$ for $20 \mathrm{~s}$. The fluorescent product was detected at the last step of each cycle and measured in the real-time reverse transcriptase PCR thermocycler, and its genomic increase of the fluorescence corresponding to the exponential increase of the product was used to determine the threshold cycle $(\mathrm{Ct})$ in each reaction using the formula $2^{-\Delta \Delta \mathrm{Ct}}$. The housekeeping gene encoding $\beta$-actin was used as a standard for all samples. All the real-time experiments were performed in triplicate, and the statistical analysis was determined using Student's $t$-test.

2.15. Western Blot Analysis. As described previously $[25,26]$, $2 \times 10^{5}$ /well PC3 prostate cancer cell line was treated with three concentrations $(5,10$ and $20 \mu \mathrm{g} / \mathrm{ml})$ of citral in $0.1 \mathrm{~mL}$ DMSO for about two days. The cells were then harvested and washed twice with cold PBS. The cell pellets were lysed using RIPA lysis buffer (Sigma-Aldrich). The controls received $0.1 \%$ DMSO. The lysates were then centrifuged at $12,000 \mathrm{rpm}$ for $20 \mathrm{~min}$ at $4^{\circ} \mathrm{C}$. The protein content of the supernatant was determined using a Bradford Protein Assay kit, and BSA was used as the standard. The total proteins $(15 \mu \mathrm{g})$ were mixed with an equal volume of $5 \times$ sample buffer containing $40 \mathrm{mM}$ of DL-dithiothreitol, boiled for $10 \mathrm{~min}$ and then loaded onto $10 \%$ sodium dodecyl sulfate-polyacrylamide gels using a Mini-Protean 3 electrophoresis cell (Bio-Rad, Hercules, CA, USA). After electrophoresis at $150 \mathrm{~V}$ in $1.5 \mathrm{~h}$, the proteins from the gels were transferred onto a polyvinyl difluoride membrane (Pall Corporation, Pensacola, FL, USA) using an electroblotting apparatus. The membrane was then blocked with 5\% skim milk (BD Difco, Franklin Lakes, NJ, USA) in PBS containing $0.1 \%(\mathrm{v} / \mathrm{v})$ Tween-20 (PBS-T) at room temperature for $1 \mathrm{~h}$ and further incubated overnight at $4^{\circ} \mathrm{C}$ with a specific monoclonal or polyclonal antibody stated previously; each of them was used at a dilution of $1: 1000$ dilution. After washing with $0.1 \%$ PBS-T three times at 10-minute intervals, the membranes were further incubated with a goat anti-rabbit IgG H\&L (HRP) secondary antibody at a 1:5000 dilution for $2 \mathrm{~h}$ RT. Finally, after washing with $0.1 \%$ PBS-T three times with a 10 minute interval between washes, the blots were developed with an ECL chemiluminescence reagent and immediately exposed to a CP-PU X-ray film (AGFA, Mortsel, Belgium). The differences in protein expression were quantified using a Molecular Imager Gel Doc XR system (Bio-Rad, Hercules, CA, USA) and normalized to actin expression on the same membrane.

2.16. DNA Fragmentation. $2 \times 10^{5} /$ well PC3 prostate cancer cell line was treated with different concentrations of citral to determine DNA fragmentation. After $48 \mathrm{~h}$ of citral treatment, the cells were trypsinized and centrifuged at $1500 \mathrm{rpm}$ for $5 \mathrm{~min}$ and supernatant was discarded. The pellet was washed twice with $1 x$ PBS. Isolation of genomic DNA was carried out by Exgene cell SV (GeneAll Biotech, Korea) according to the manufacturer's instruction. DNA concentration was quantified using nanodrop, and equal volume of DNA (200 ng) was loaded with $6 \times$ loading buffer and run onto $0.8 \%$ agarose gel electrophoresis containing ethidium bromide in a Mini Gel Tank containing tris-borate-EDTA 
TABle 1: Primers listed in the present study.

\begin{tabular}{lccc}
\hline S.no. & Genes & Forward primer $\left(5^{\prime}-3^{\prime}\right)$ & Reverse primer $\left(5^{\prime}-3^{\prime}\right)$ \\
\hline 1 & HMGR & CTTGTTCATGCTCACAGTCG & ACCAGCATAGGTTCACGTCTA \\
2 & $F A S N$ & AACGGCAACCTGGTAGTGAG & GTGTCCATGAAGCTCACCCA \\
3 & SREBP1 & GATGCGGAGAAGCTGCCTAT & GCTGTGTTGCAGAAAGCGAA \\
4 & ACC & TGGTTCTTGGGTTGTGATCGA & TCGGTCAGCGTACATCTCCAT \\
5 & BAX & TTCTGACGGCAACTTCAACTG & GTTCTGATCAGTTCCGGCA \\
6 & Bcl-2 & AGCACTCCCGCCACAAAGA & GAGGCAAGCATAAGACTGG \\
7 & $\beta$-actin & CATCACTATCGGCAATGAGC & GACAGCACTGTGTTGGCATA \\
\hline
\end{tabular}

for $2 \mathrm{~h}$ at $80 \mathrm{~V}$. The gel was then examined under ultraviolet light and photographed.

2.17. Oil Staining. The lipids in cancer cells were visualized using Oil Red O Staining. As described previously [25, 26], cells were washed with PBS and fixed in $4 \%$ paraformaldehyde for about $30 \mathrm{~min}$. Later, the cells were stained using $0.5 \%$ Oil Red Staining Solution for $15 \mathrm{~min}$ in $60^{\circ} \mathrm{C}$. Finally, the stained cells were washed thrice with $1 \times \mathrm{PBS}$ and were photographed under the light microscope.

2.18. Data Analysis. Antiproliferative activity was indicated as $50 \%$ inhibitory concentration $\left(\mathrm{IC}_{50}\right)$ of the compound that decreased the cell viability up to $50 \%$ compared with untreated controls. The $\mathrm{IC}_{50}$ values were determined using GraphPad Prism 5 software program (GraphPad Software, La Jolla, CA). The $\mathrm{IC}_{50}$ values of all cancer cell lines and treatments were significantly different from one another when their 95\% confidence limits (CLs) did not overlap. The percentage of growth inhibition was determined using the formula: $\%$ growth inhibition $=(\mathrm{ODt} / \mathrm{ODc}) \times 100$, where ODt and ODc are the absorbance values of treated and untreated cells, respectively. All the experiments were performed in triplicate and the data are expressed as mean \pm SE. The statistical differences among means have been analyzed by performing Student's $t$-test using GraphPad Software. The data represent significant values as ${ }^{*} p<0.05,{ }^{* *} p<0.01$, and ${ }^{* * *} p<0.001$, respectively.

\section{Results}

3.1. Isolation of Citral from Cymbopogon citratus Oil. The major active constituent citral was isolated and identified through various spectroscopic analyses, including electron ionized mass spectrometry (EI-MS) and nuclear magnetic resonance (NMR) spectroscopy. Citral was identified based on the following evidence: a colorless oil; UV (methanol): $\lambda_{\max } \mathrm{nm}=233$; EI-MS $(70 \mathrm{eV}), m / z$ (\% relative intensity): $152[\mathrm{M}]^{+}(6.4), 137$ (3.8), 94 (12.5), 84 (24.6), 69 (100), 59 (3.40), 41 (87.3), ${ }^{1} \mathrm{H}$ NMR (DMSO, $\left.600 \mathrm{MHz}\right): \delta$ $1.62(3 \mathrm{H}, \mathrm{s}), 1.67(3 \mathrm{H}, d, J=1.2 \mathrm{~Hz}), 2.00(2 \mathrm{H}, \mathrm{s}), 2.18(3 \mathrm{H}$, $\mathrm{m}), 2.62(2 \mathrm{H}, \mathrm{t}), 5.20\left({ }^{1} \mathrm{H}, \mathrm{m}\right), 5.83\left({ }^{1} \mathrm{H}, \mathrm{t}\right), 9.96\left({ }^{1} \mathrm{H}, \mathrm{d}\right.$, $J=8.16 \mathrm{~Hz}) .{ }^{13} \mathrm{C} \mathrm{NMR}\left(\mathrm{CDCl}_{3}, 150 \mathrm{MHz}\right): \delta 192.4 \mathrm{~d}(\mathrm{C}-1)$, $166.1 \mathrm{~s}$ (C-3), $134.4 \mathrm{~s}$ (C-7), $128.4 \mathrm{~d}$ (C-2), $123.5 \mathrm{~d}$ (C-6), 40.4 t (C-4), 26.9 t (C-5), 25.1 q (C-8), 18.1 q (C-9), 17.8 q (C-10) (Supplementary Figure S1).
3.2. Pharmacokinetic and Biological Activity Prediction of Neral and Geranial. Cis-citral and trans-citral (Figure 1) molecules were further evaluated for their drug-like behavior and pharmacokinetic properties using SwissADME and PreADMET web servers based on relevant chemical descriptor. The calculated properties such as molecular weight, octanol/water partition coefficient, plasma protein binding (PPB) (<90\%: weakly bound chemicals; >90\%: strongly bound chemicals), human intestinal absorption (HIA) (0 20\% is poorly absorbed, 20 70\% is moderately absorbed, and 70 100\% is well absorbed), CYP2D6 inhibition (either inhibitor or noninhibitor), toxicity based on rodent carcinogenicity ( + is noncarcinogen and - is carcinogen), and blood-brain barrier (BBB) activity in CNS (>2.0 is high absorption, $2.0 \sim 0.1$ is middle absorption, and $<0.1$ is low absorption) were measured for citral molecule. In addition, Lipinski's rule of five was used for the determination of drug-likeness properties, such as molecular weight less than 500, fewer than $5 \log p$ value octanol-water partition coefficient, fewer than 5 hydrogen bond donors, and fewer than 10 hydrogen bond acceptors. The detailed analyses of predicted ADMET values of neral and geranial with acceptable range are given in Table 2 . All possible biological activities were predicted with probability of active $\left(P_{\mathrm{a}}\right)$ and probability of inactive $\left(P_{\mathrm{i}}\right)$ scores using PASS program. The predicted probability score ranges from 0 to 1 and $P_{\mathrm{a}}>0.7$ probability scores considered that our molecule has high chance to act as a biological function. The accuracy neral and geranial biological activity measured based on the $P_{\text {a }}$ score and the biological activity related to the apoptosis induced cancer were listed in Table 3. Finally, drug-likeness, ADMET, and predicted biological activity results showed that neral and geranial molecules can act as potential druglike molecule and considered for further experiments.

3.3. Molecular Interactions of Neral and Geranial. The crystal structure of FASN and Bcl-2 was used to conduct molecular docking simulation using AutoDock Vina. The known inhibitors of navitoclax (ABT-263) and orlistat structural coordinates were retrieved from $\mathrm{Bcl}-2$ and FASN protein structures and used as control ligands for docking reproducibility, while checking the interaction results of the known inhibitor navitoclax (Bcl-2) and orlistat (FASN) yielded a binding affinity of $-9.6 \mathrm{kcal} / \mathrm{mol}$ and $-6.4 \mathrm{kcal} / \mathrm{mol}$, respectively. Further, protein-ligand molecular interactions were confirmed by their binding affinity and interaction residues between the active site residues of proteins. Our 


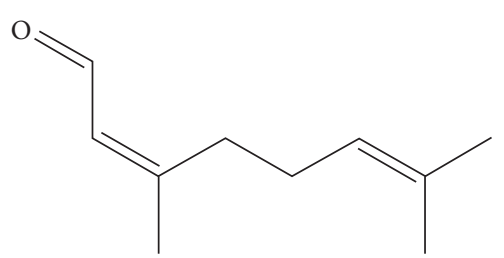

(a)

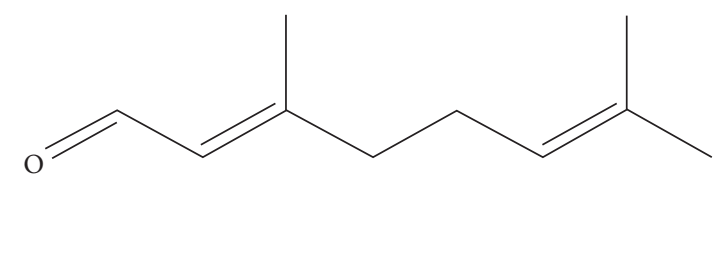

(b)

FIgURE 1: Structure of cis- and trans-citral. (a) Neral. (b) Geranial.

TABLE 2: ADMET characteristic of cis-citral and trans-citral.

\begin{tabular}{|c|c|c|c|c|c|c|c|c|}
\hline Molecule & $\begin{array}{c}\text { Molecular } \\
\text { weight }\end{array}$ & $\begin{array}{l}\log \\
P_{\mathrm{o} / \mathrm{w}} \\
\end{array}$ & $\begin{array}{c}\text { Plasma protein } \\
\text { binding }(\%)\end{array}$ & $\begin{array}{c}\text { Human intestine } \\
\text { absorption (\%) }\end{array}$ & CYP2D6 & $\begin{array}{l}\text { Toxicity } \\
\text { (R) }\end{array}$ & $\begin{array}{c}\text { Blood-brain } \\
\text { barrier }\end{array}$ & $\begin{array}{l}\text { Lipinski's } \\
\text { violations }\end{array}$ \\
\hline $\begin{array}{l}\text { cis-citral } \\
\text { (neral) }\end{array}$ & 154.25 & 2.74 & 100 & 100 & Noninhibitor & - & 6.7413 & Nil \\
\hline $\begin{array}{l}\text { trans-citral } \\
\text { (geranial) }\end{array}$ & 152.23 & 2.71 & 100 & 100 & Noninhibitor & + & 2.00829 & Nil \\
\hline
\end{tabular}

$\log P_{\mathrm{o} / \mathrm{w}}$ : octanol/water partition coefficient; PPB: plasma protein binding ( $<90 \%$ is weakly bound chemicals and $>90 \%$ is strongly bound chemicals); HIA: human intestinal absorption ( $0 \sim 20 \%$ is poorly absorbed, $20 \sim 70 \%$ is moderately absorbed, and $70 \sim 100 \%$ is well absorbed); toxicity: rodent carcinogenicity (R: Rat, + is noncarcinogen and-is carcinogen); BBB: blood-brain barrier activity in CNS ( $>2.0$ is high absorption, $2.0 \sim 0.1$ is middle absorption, and $<0.1$ is low absorption).

TABle 3: Prediction of activity spectra for substances (PASS).

\begin{tabular}{lccc}
\hline S. no. & Predicted biological activity & $P_{\mathrm{a}}$ & $P_{\mathrm{i}}$ \\
\hline 1 & Apoptosis agonist & 0.826 & 0.006 \\
2 & Fatty-acyl-CoA synthase inhibitor & 0.784 & 0.005 \\
3 & TP53 expression enhancer & 0.747 & 0.018 \\
4 & Farnesyltransferase inhibitor & 0.6559 & 0.002 \\
5 & Chemoprotective & 0.625 & 0.004 \\
6 & MMP9 expression inhibitor & 0.626 & 0.013 \\
7 & HMOX1 expression enhancer & 0.616 & 0.017 \\
8 & Transcription factor stimulant & 0.590 & 0.010 \\
9 & TNF expression inhibitor & 0.590 & 0.014 \\
10 & Transcription factor NF kappa B stimulant & 0.590 & 0.010 \\
11 & Immunostimulant & 0.608 & 0.022 \\
12 & Lipid metabolism regulator & 0.594 & 0.022 \\
13 & Caspase 3 stimulant & 0.588 & 0.018 \\
14 & Anticarcinogenic & 0.539 & 0.016 \\
15 & HMG CoA synthase inhibitor & 0.382 & 0.004 \\
16 & Prostate cancer treatment & 0.401 & 0.022 \\
17 & Antioxidant & 0.385 & 0.013 \\
\hline
\end{tabular}

result indicates that both neral and geranial have interacted with FASN (Figure $2(\mathrm{a})$ ) with $-6.3 \mathrm{Kcal} / \mathrm{mol}$ and $-6.4 \mathrm{Kcal} /$ mol, respectively. The neral and geranial interaction with Bcl-2 (Figure 2(b)) yielded a docking score that was found to be $-5.2 \mathrm{Kcal} / \mathrm{mol}$ and $-5.3 \mathrm{Kcal} / \mathrm{mol}$, respectively (Table 4 ). Based on these results, we have taken our study to the next level to identify the role of citral isomers in prostate cancers.

3.4. Citral Inhibited Cell Viability, Proliferation, and Clonogenic Potential of Prostate Cancer (PC3 and PC-3M) Cells. To determine the effect of citral on the proliferation of prostate cancer cells (PC3 and PC-3M), MTT assay was performed. We determined that the treatment of citral in a dose-dependent manner inhibited the cell viability of prostate cancer cells (Figure 3(a)). After 72 hours of incubation, $\mathrm{IC}_{50}$ of citral in
PC3 and PC-3M cells was found to be 10 and $12.5 \mu \mathrm{g} / \mathrm{ml}$, respectively (Figure 3(a)). The citral showed strong inhibitory action in PC3 compared to PC-3M. Later, we performed colony formation assay to evaluate the clonogenic survival of prostate cancer cells after citral treatment. From the result, we found that citral can inhibit the colony formation of PC3 cells in a dose-dependent manner (Figure 3(b)). Results indicated that citral reduced the colony formation significantly compared to that of untreated cancer cells (Figure 3(b)). These results conclude that citral treatment to prostate cancer cells reduces the cell viability, proliferation, and clonogenic potential of cancer cells.

\subsection{Citral Induced Altered Morphological Characteristics of} Cancer Cells. The morphological characteristics of prostate cancer cells were monitored after different concentrations of citral treatment. The results showed that both PC3 and PC3M cells upon $5 \mu \mathrm{g} / \mathrm{ml}$ citral treatment exhibited gradual increase in morphological alteration and reached its maximum when cells were treated with $100 \mu \mathrm{g} / \mathrm{ml}$ of citral. When compared to untreated cells which showed $90 \%$ confluent, treated cells exhibited distinct morphological pattern including shrunken and shape-less phenotype. In addition, the cell size and number were also significantly reduced which showed that citral resulted in the detachment of cells and caused alternation in morphology (Figures 4(a) and 4(b)).

3.6. Citral Inhibited Lipogenesis of Cancer Cells. During cancer, an abnormal cell proliferation happens for which lipogenesis pathway plays a crucial role. To determine how the citral treatment interferes on lipid metabolism of cancer cells, we treated PC3 cells with two different concentrations of citral $(10$ and $20 \mu \mathrm{g} / \mathrm{ml}$ ) for 2 days, and ORO staining was carried out. The control cells clearly showed the accumulation of lipid droplets in an intact cell (Figure 5(a)-A). However, when the 


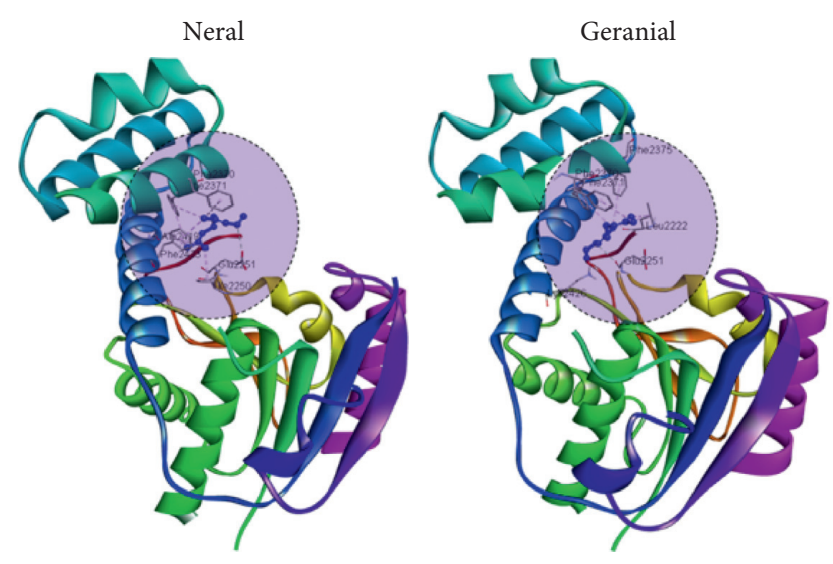

(a)
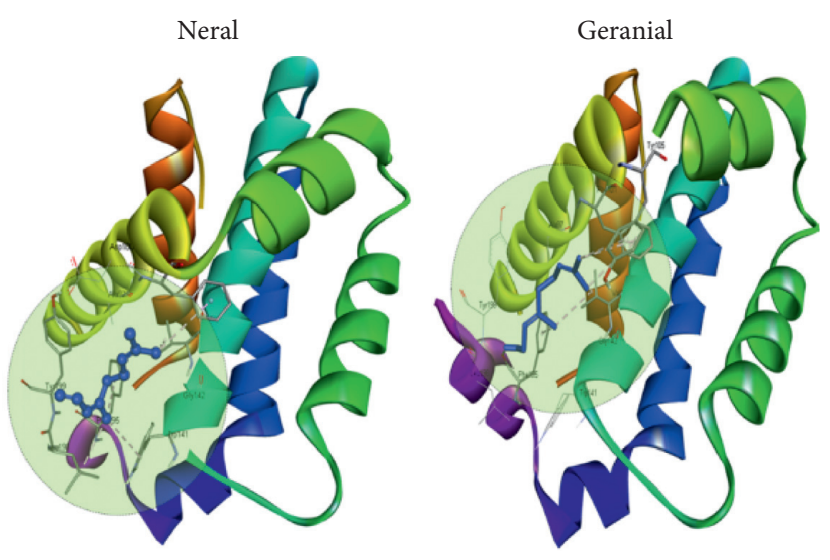

(b)

Figure 2: Molecular interaction studies of neral and geranial. (a) FASN. (b) Bcl-2. The amino acids involved in hydrogen bonding formation were represented in respective three-letter codes and the arrows indicate their hydrogen bond interaction. The threedimensional protein structures and ligands were visualized in solid ribbon style followed by a rainbow color and ball and stick style (blue), respectively.

TABLE 4: Molecular interaction analysis of neral and geranial against each target protein.

\begin{tabular}{lccc}
\hline Proteins & Molecules & Docking energy $(\mathrm{Kcal} / \mathrm{mol})$ & Interaction residues \\
\hline \multirow{2}{*}{ FASN } & Neral & -6.3 & ILE2250, LEU2251, PHE2323, PHE2370, PHE2371, ALA2419, PHE2423 \\
& Geranial & -6.4 & LEU2222, GLU2251, PHE2370, PHE2371, PHE2375 \\
\hline \multirow{2}{*}{ Bcl-2 } & Neral & -5.2 & ALA97, ASP100, PHE101, TRP141, GLY142, VAL145, TYR199, PHE195, LEU198 \\
& Geranial & -5.3 & ALA97, PHE101, TYR105, TRP141, GLY142, VAL145, PHE195, LEU198, TYR199 \\
\hline
\end{tabular}

(A)

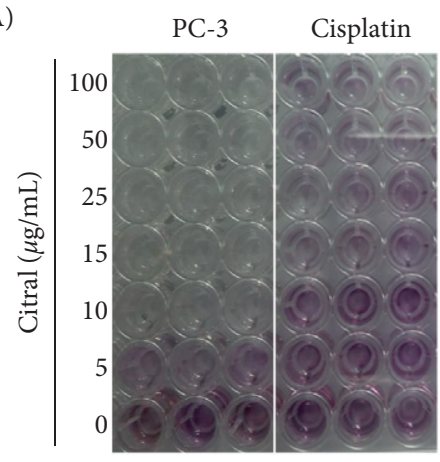

(B)
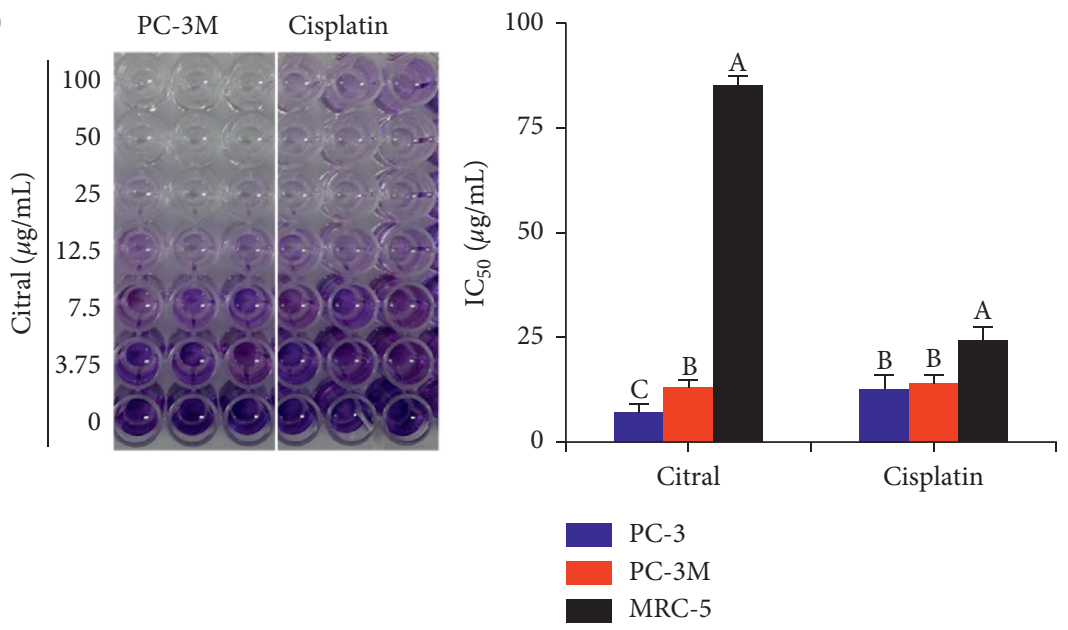

(a) 

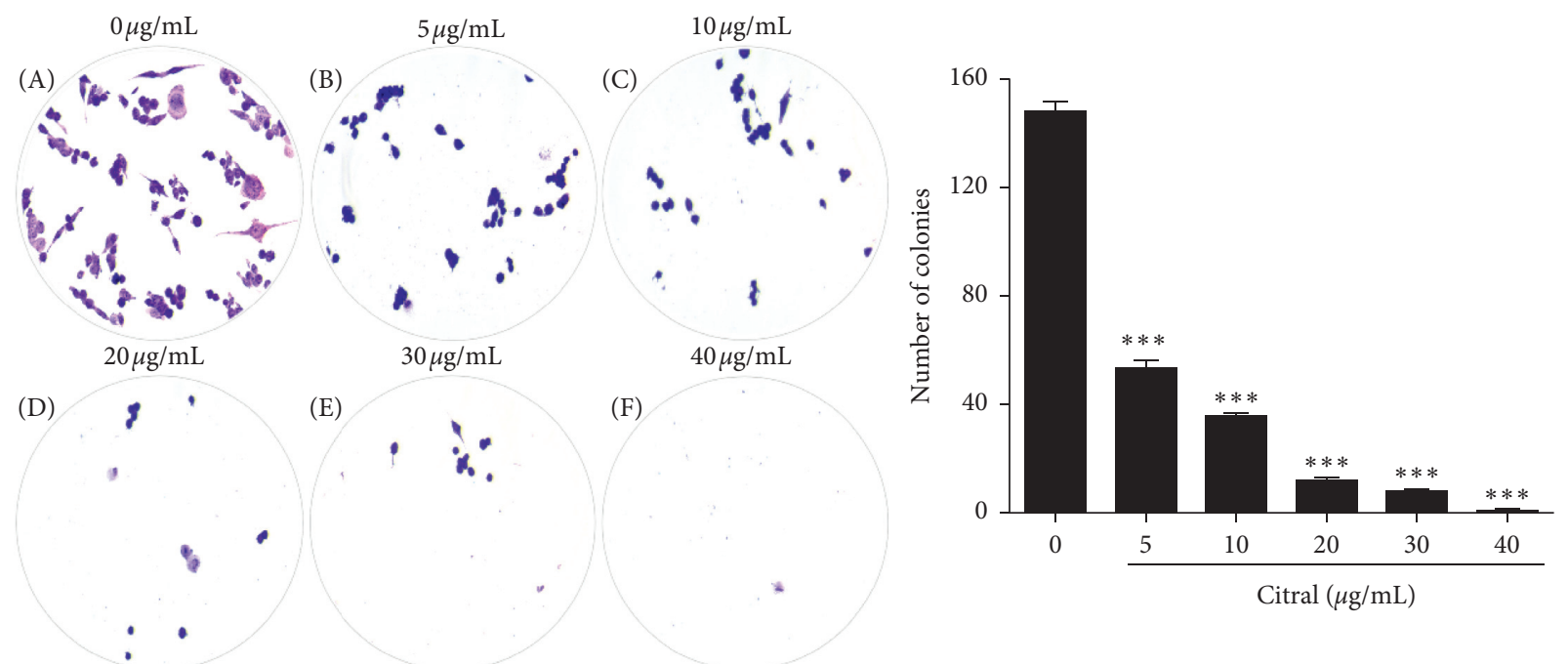

(b)

FIGURE 3: Citral treatment resulted in cell viability and decreased colony formation. (a) Inhibitory concentration ( $\left.\mathrm{IC}_{50}\right)$ of citral of PC3 and PC3M prostate cancer cells was compared with positive control cisplatin. Cell toxicity of citral was compared with normal cell line MRC-5. (b) Citral inhibited the clonogenic formation of prostate cells in a dose-dependent manner. Colonies were stained with crystal violet staining and counted using ImageJ software. Each bar represents the mean \pm SE of duplicate samples of three independent experiments $\left({ }^{* * *} p<0.001\right.$ using Student's $t$-test).

$0 \mu \mathrm{g} / \mathrm{mL}$

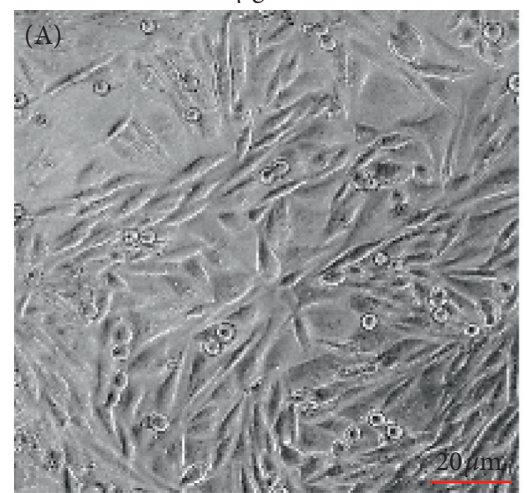

$20 \mu \mathrm{g} / \mathrm{mL}$

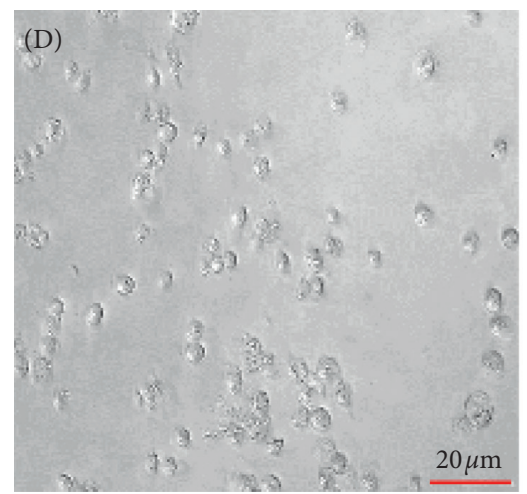

$5 \mu \mathrm{g} / \mathrm{mL}$

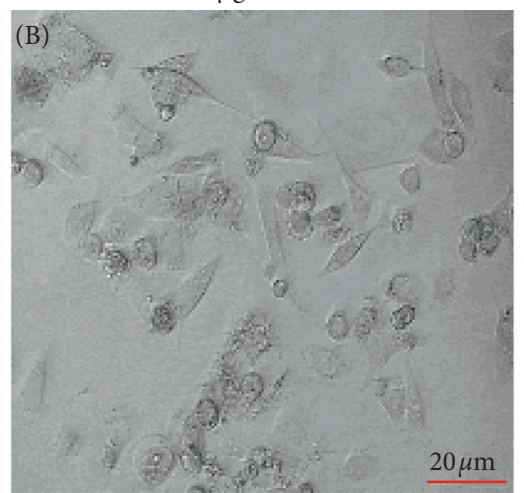

$30 \mu \mathrm{g} / \mathrm{mL}$

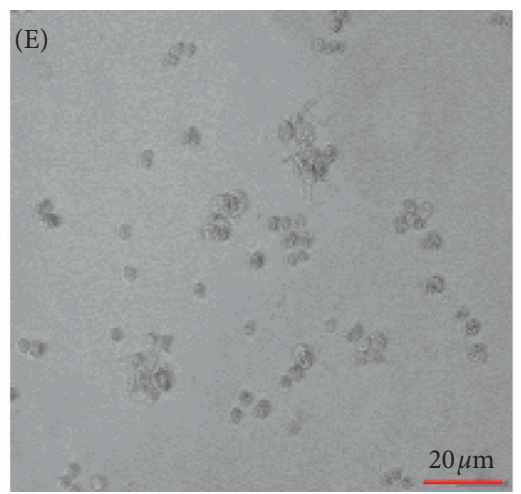

(a)
$10 \mu \mathrm{g} / \mathrm{mL}$

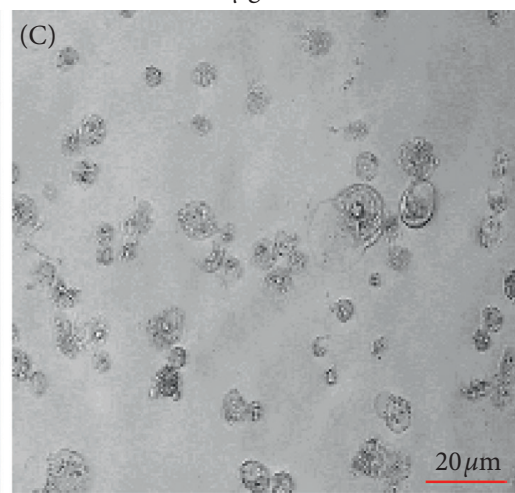

$40 \mu \mathrm{g} / \mathrm{mL}$

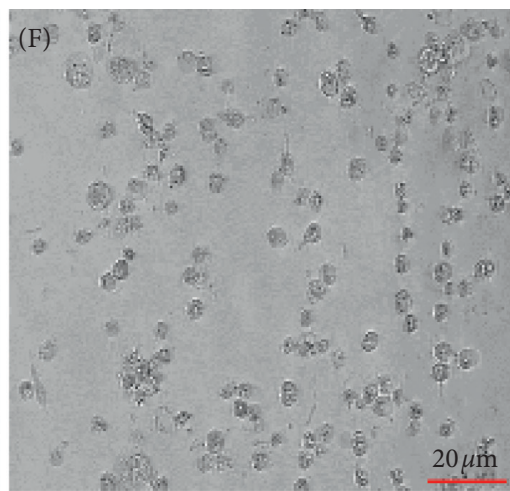

FIgURE 4: Continued. 


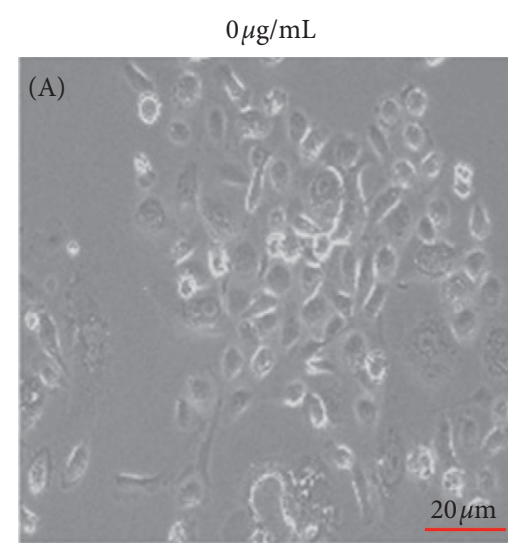

$20 \mu \mathrm{g} / \mathrm{mL}$

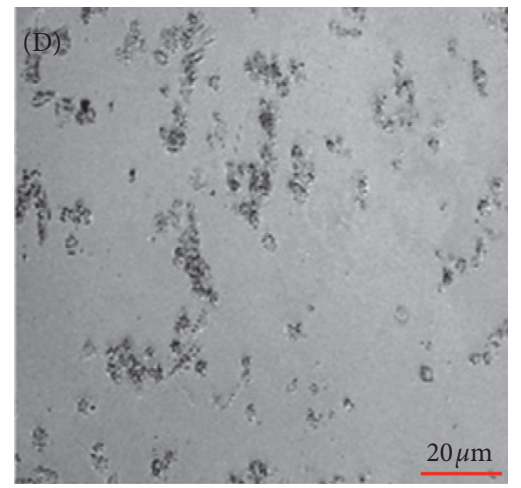

$5 \mu \mathrm{g} / \mathrm{mL}$

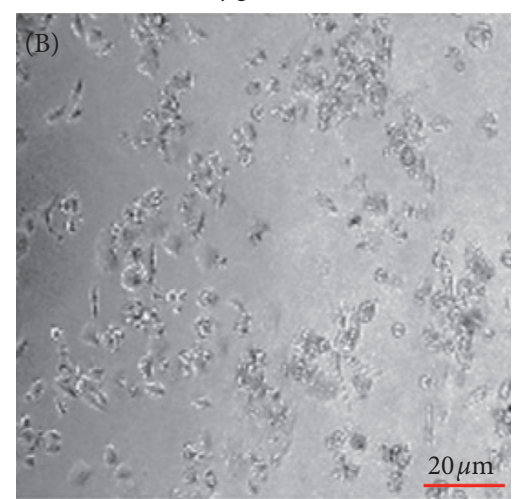

$30 \mu \mathrm{g} / \mathrm{mL}$

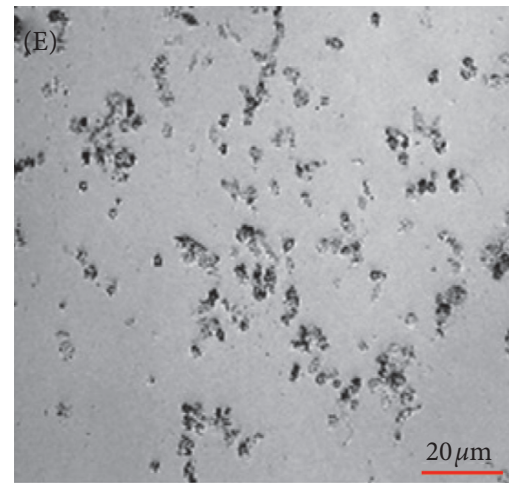

(b)
$10 \mu \mathrm{g} / \mathrm{mL}$

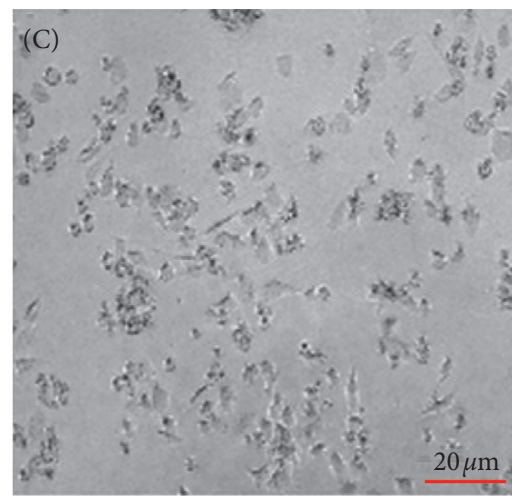

$40 \mu \mathrm{g} / \mathrm{mL}$

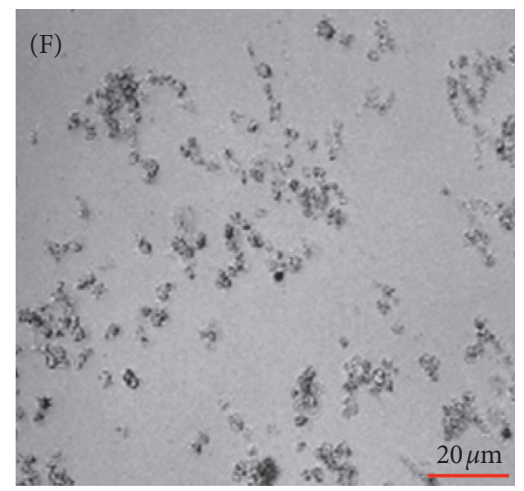

FIGURE 4: Morphological changes in prostate cancer cells. Morphological characteristics of prostate cancer cells (PC3M and PC3) were observed with a phase-contrast microscope (a) and (b). The inhibition of growth by treating different concentrations of citral was observed by showing distinct morphology. Images are representative of three independent replicates.

cells were treated with citral, the cells were significantly damaged and resulted in the expulsion of lipid droplets and thus inhibited the survival of cancer cell (Figure 5(a)-B and C). To further confirm the role of citral on the inhibition of lipogenesis, we have studied the genes and proteins involved in AMPK pathway. In Figure 5(f), the activation of AMPK protein expression resulted in the downregulation of AMPK pathway genes such as SREBP1 (0.308-fold), ACC (0.32 fold), and HMGR (0.212-fold), respectively (Figures 5(b)-5(e)), and its downregulation is well correlated with decreased protein expression (Figure 5(f)) except FASN (0.15-fold) which showed very less protein expression at high concentration compared with other genes.

3.7. Citral Treatment Induced Apoptosis of Cancer Cells. To determine citral treatment induced apoptosis, we used various apoptosis detection methods to identify whether citral induced cancer cell death was due to apoptosis. At first, we used Hoechst staining to confirm citral initiated apoptosis in cancer cells. Under nontreated condition, the cancer cell membrane remained intact such that the dye was unable to diffuse into the nuclei and hence no fluorescence was detected (Figure 6(a)-A). In contrast, cancer cells treated with different concentrations of citral caused cell membrane damage and thus the dye was able to penetrate the cell and thus stained the nuclei (Figure 6(a)-B and C). Secondly, we used PI staining to determine the cell viability and apoptosis of both treated and untreated cells. Control cells do not exhibit any fluorescence when stained with PI indicating that the cells remained intact (Figure 6(b)-A). Cells treated with 10 or $20 \mu \mathrm{g} / \mathrm{ml}$ of citral reduced the cell viability and cell number indicating that citral treatment damaged cell membrane and thus resulted in red fluorescence (Figure 6(b)-B and C). Next, we performed annexin-V-FITC labeling to identify both early and late stage apoptosis on citral treatment. The untreated cells showed $99.1 \%$ of live cells with at least early and late apoptosis and necrosis (Figure 6(c)A). However, the cells treated with 10 or $20 \mu \mathrm{g} / \mathrm{ml}$ of citral exhibited the significant accumulation of late apoptotic cell (33.6\% and 60.1\%) and early apoptotic cell (53.5\% and $44.9 \%)$, respectively (Figure 6(c)-B and C). Later, DNA fragmentation assay was performed for both treated and nontreated cancer cells. Control wells possessed intact DNA which is devoid of degradation. However, the cells treated with different concentrations of citral resulted in fragmentation of DNA in a dose-dependent manner (Figure 6(d)-A and B). Finally, we studied the genes and proteins that are regulated by citral treatment. The different concentrations of citral (5, 10 and 20 $\mu \mathrm{g} / \mathrm{ml}$ ) were treated to PC-3 cells for $48 \mathrm{~h}$ and mRNA expression patterns of apoptosis related pathway genes such as $B A X$ (Bcl-2-associated X protein) and $B c l-2$ were analyzed. In $5 \mu \mathrm{g} / \mathrm{ml}$ treatment, the $\mathrm{Bcl}-2$ gene gradually decreased up to 
0.67 -fold and greatly decreased up to 0.15 -fold with $20 \mu \mathrm{g} / \mathrm{ml}$ of treatment (Figure 6(e). In contrast, the expression profile of $B A X$ was also upregulated in a gradual manner (Figure 6(e)). To determine whether the alteration in gene pattern changes protein expression, we performed Western blot analysis. From the results, we conclude that treatment of citral has resulted in the induction of BAX and downregulation of Bcl-2 (Figure 6(f)).

\section{Discussion}

In the 1990s, prostate cancer was not considered as an important issue in Asia due to its low prevalence rate [1]. However, in recent years, a dramatic increase of prostate cancer has drained the attention of many researchers to actively participate in prostate cancer related researches. According to the National Health Insurance Corporation, the number of prostate cancer patients in outpatient clinics increased from 4843 men (2002) to 20498 men (2010), respectively. The current treatments for treating prostate cancer are limited because the patients poorly respond to the treatment and metastatic disease can gradually develop even after radical prostatectomy [27]. Therefore, identifying the drug target that kills the metastatic cells is extremely important to overcome this deadly disease. Complementary and alternatives medicines from traditional medicinal plants containing active bioactive principles aid to target the molecular pathways in cancer and thus prevent the progression of the disease with little or no side effects [28].

Citral is a mixture of two stereoisomeric monoterpene aldehydes such as the cis-citral (neral) and trans-citral (geranial). It is also found in several plants including Melissa and lemon. Lemongrass oil is used as the main ingredient in cosmetics, food, and perfumes and has a wide range of therapeutic properties including antibacterial, antifungal, analgesic, and antispasmodic properties and has an effect on the central nervous system not only on cancer. The therapeutic use of this oil was due to the presence of monoterpenes and myrcene. Few studies demonstrated the anticancer properties of citral in various cancer cell lines including breast (MDI-MB-231), small-cell lung cancer, colorectal cancer (HCT116 and HT29), and cervical cancer (HeLa and ME-180) [12, 29-31]. Although various studies in a preliminary level of citral have been studied against various cancer cell lines, the effect of cis- and trans-citral on aggressive prostate cancer (PC3) has not been elucidated so far. In our present study, we have isolated monoterpene (citral) from lemongrass and investigated the anticancer effects against prostate cancer cells. Our results conclude that citral treated to PC3 induced apoptosis via the lipogenesis pathway.

Studying cancer metabolism has become a new trend in the field of cancer research [32]. In general, cancer cell metabolism greatly varies from that of normal cells which involves abnormal activation of glycolysis and elevated lipid biosynthesis by modulating various genes and proteins [33]. Prostate cancers are highly dependent on altered lipid metabolism and enhanced cholesterol biosynthesis for its survival [34]. Understanding how lipid biosynthesis influences the proliferation of cancer cells will aid in attaining the knowledge of the link between cellular metabolism and inhibition of cancer cell growth, ultimately leading to the development of drugs in human cancer treatments. With the previous evidence, there is a significant motivation developed to investigate the changes in lipid metabolism of prostate cancer with or without citral isomers treatment. During the last decade, targeting the apoptosis pathway is considered a potential way to treat various diseases including cancers. For this purpose, we have isolated and identified the active principle from lemongrass oil. The constituent was determined to be citral which is a monoterpene that exhibited significant antiproliferative activity toward prostate cancer cell lines (PC-3 and $\mathrm{PC} 3 \mathrm{M}$ ).

To attain the knowledge of how citral isomers alter cancer cell metabolism and result in apoptosis, we used in silico studies to identify whether neral and geranial could be target drugs by showing strong biological activity, drug candidates, and essential role in cancer cell metabolism by undergoing apoptosis. At first, the effect of citral on biological activity was studied using the PASS program and predicted that citral showed strong biological activity in inhibiting lipogenesis and inducing apoptosis (Table 3 ). The bioavailability of the drug is essential for any drug to exhibit pharmacological property. Therefore, we studied ADMET to predict the drug likeliness of cis-citral and trans-citral. From Table 2, we identified that both cis and trans forms were well absorbed in the intestine (100\%) and have a strong binding capacity $(100 \%)$. For the protein-ligand interaction studies, we have selected the specific target proteins which are involved in lipogenesis and apoptosis pathway including FASN and Bcl-2 because prostate cancer survival depends on the lipogenesis pathway. Interaction studies demonstrated that cis-neral and trans-geranial could bind to the active site of each protein and thus left the way to study these proteins in vitro.

Several studies demonstrated that the upregulation of genes involved in lipogenesis and cholesterol synthesis is essential for the survival of a wide variety of tumor cells. Interestingly, there is no cytotoxicity of normal cells developed while inhibiting the expression of FASN and ACC. This denotes that normal cell growth relies on the fat from the dietary or culture medium and is less dependent on de novo fatty acid synthesis whereas the cancer cells purely addicted to de novo fatty acid synthesis. Fatty acid synthesis is associated with the activation of AMPK, a crucial enzyme that is required for modulating AMP/ATP ratio in the fatty acid synthesis [35]. A previous report suggests that the activation of AMPK through phosphorylation inhibits ACC, FASN, SREBP1, and other lipogenesis enzymes, which is the distinctive feature of most of the tumor cells $[36,37]$. Studies have shown that the activators of AMPK such as 5-aminoimidazole-4-carboxamide riboside or the thiazolidinedione rosiglitazone could diminish the lipid synthesis including phospholipids and cholesterol and thus result in the inhibition of cell migration and proliferation of cancer cell. These findings suggest that AMPK is the right target to consider in the treatment of cancer. Activated AMPK 

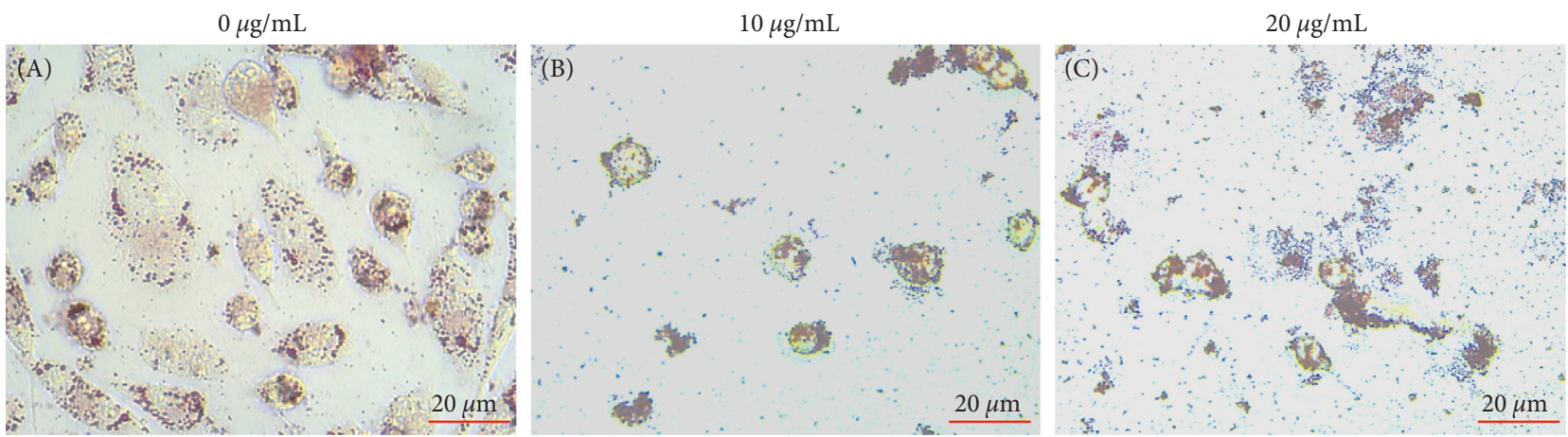

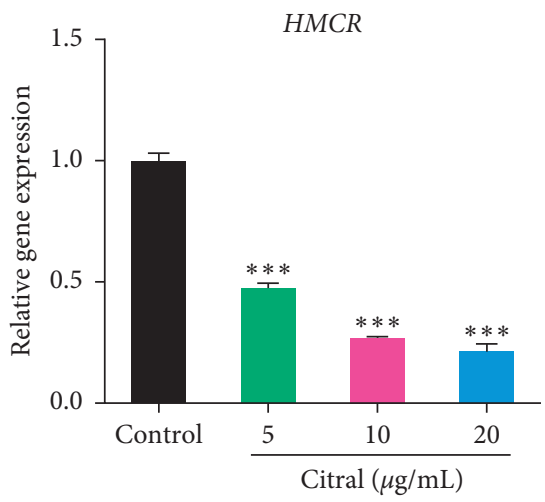

(b)

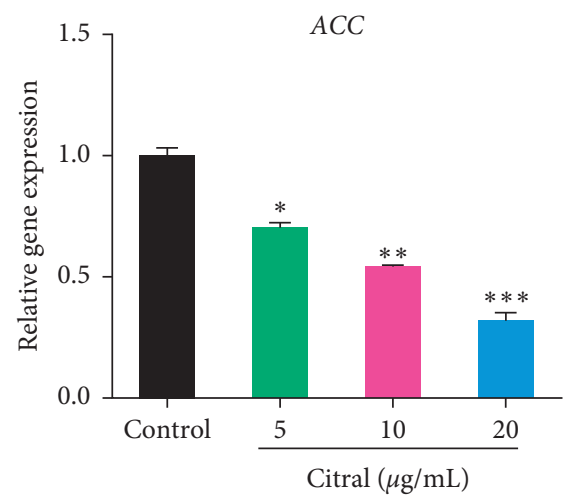

(e)

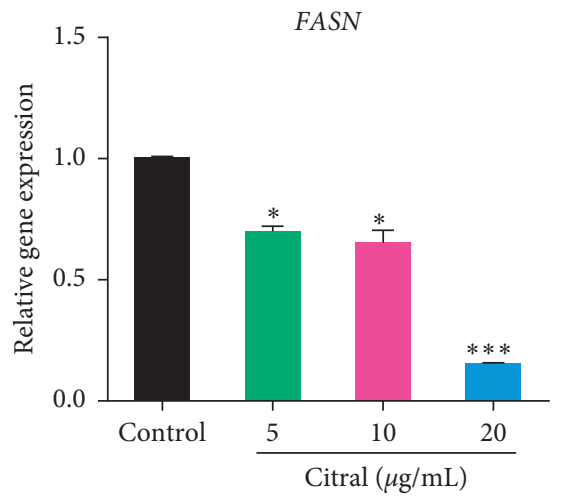

(c)

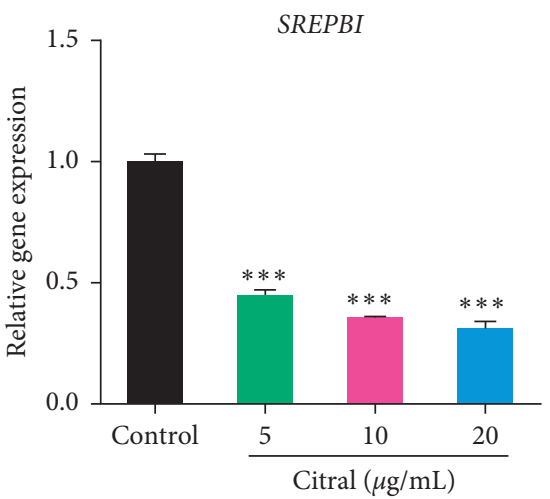

(d)

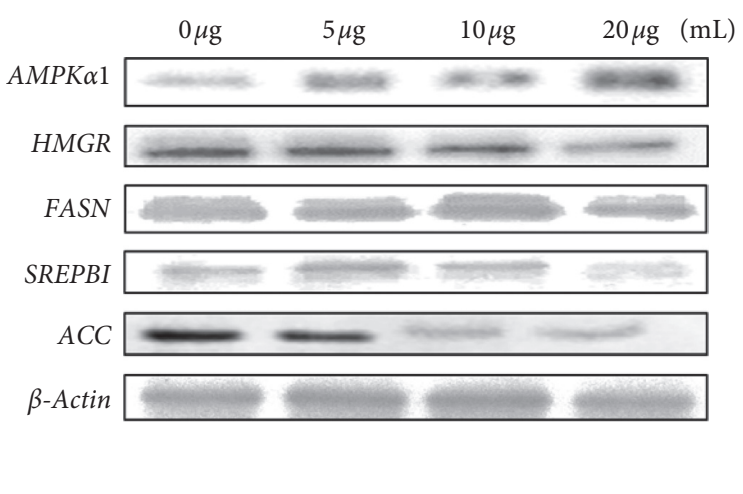

(f)

FIgURE 5: Citral suppressed lipogenesis of prostate cancer cells. (a) Oil Red O staining was used to identify the lipid droplets in prostate cancer cells (PC3) with $(65.7$ and $131.4 \mu \mathrm{M})$ or without treatment. (b-e) The mRNA expression analysis of various transcripts involved in the lipogenesis pathway was quantified using qPCR analysis. The $\beta$-actin was used as an internal control. (f) The protein expression of AMPK-P, HMGR, FASN, SREBP1, and ACC was quantified using Western blotting. Each bar represents the mean \pm standard error of triplicate samples from three independent experiments ( $p=0.05$, using Student's $t$-test).

directly phosphorylates (AMP and ADP) a number of substrates to acutely impact the metabolism and growth, as well as phosphorylating a number of transcriptional regulators that mediate long-term metabolic reprogramming [38]. When elevated AMP is bound to the $\gamma$ subunit, the inhibitory domain of the $\alpha 1$ subunit is released from the kinase domain. This results in an active conformation of AMPK, which allows the upstream kinases, such as LKB1, to phosphorylate Thr172 on AMPK $\alpha$ [39]. Our present study showed that the treatment of citral activated AMPK phosphorylation by the activation of gene and protein levels and thus inhibited the enzymes involved in fatty acid and cholesterol biosynthesis such as SREBP1 and HMGR. Additionally, the activation of AMPK also resulted in the activation of BAX and downregulated the Bcl-2 and thus resulted in apoptosis. The apoptosis induction by citral was also inconsistent with the results of Hoechst, PI staining which caused fluorescence in dead and damaged nuclei, FACS which identified early and late apoptotic cells, and DNA fragmentation which visualized degradation of DNA (Figures 6(a)-6(f)). 
(a)

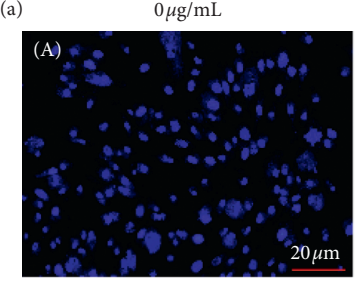

(b)

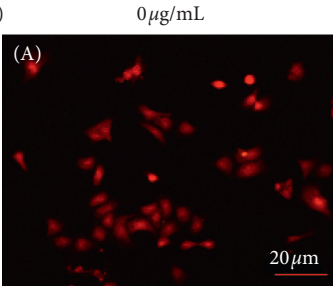

(c) $\quad 0 \mu \mathrm{g} / \mathrm{mL}$

(A) Specimen_003-Tube_001

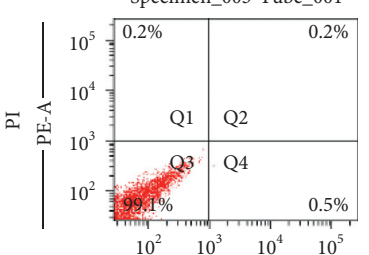

(d) (A)

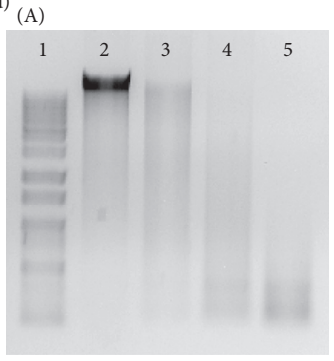

$(\mathrm{e})$

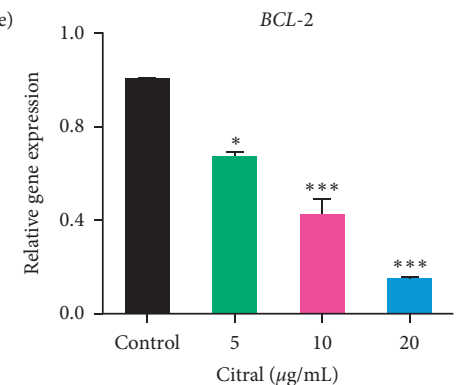

(B)
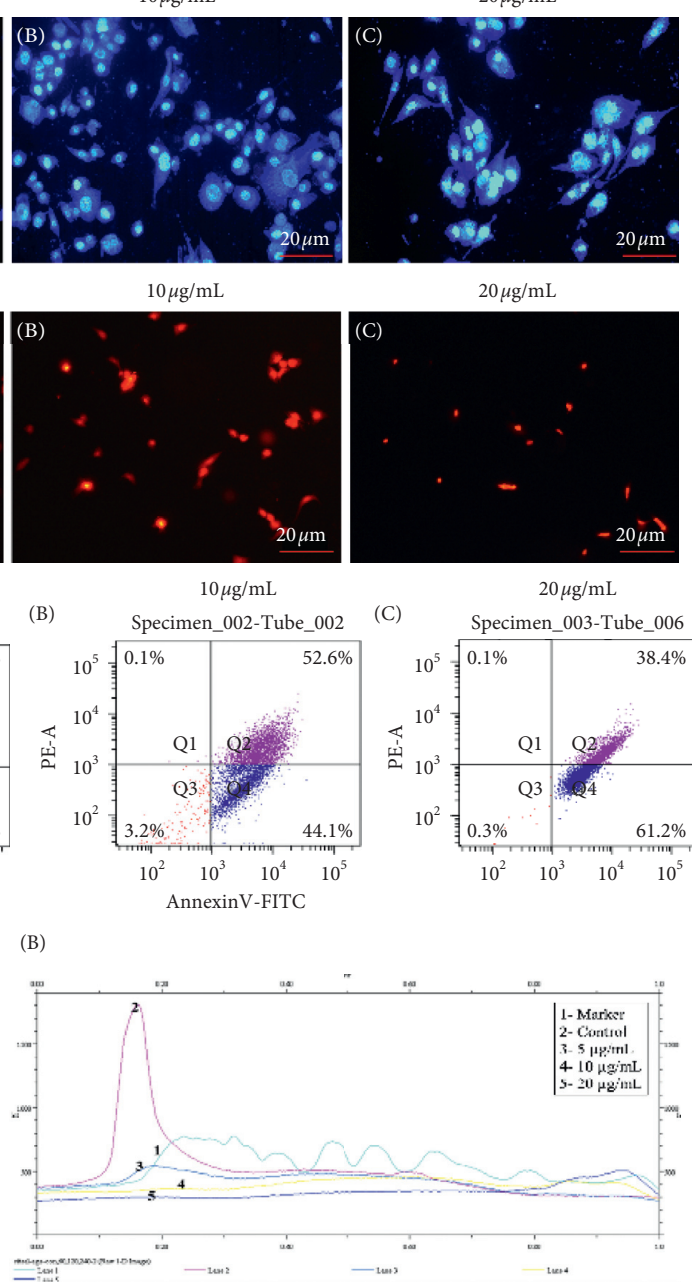

$20 \mu \mathrm{g} / \mathrm{mL}$
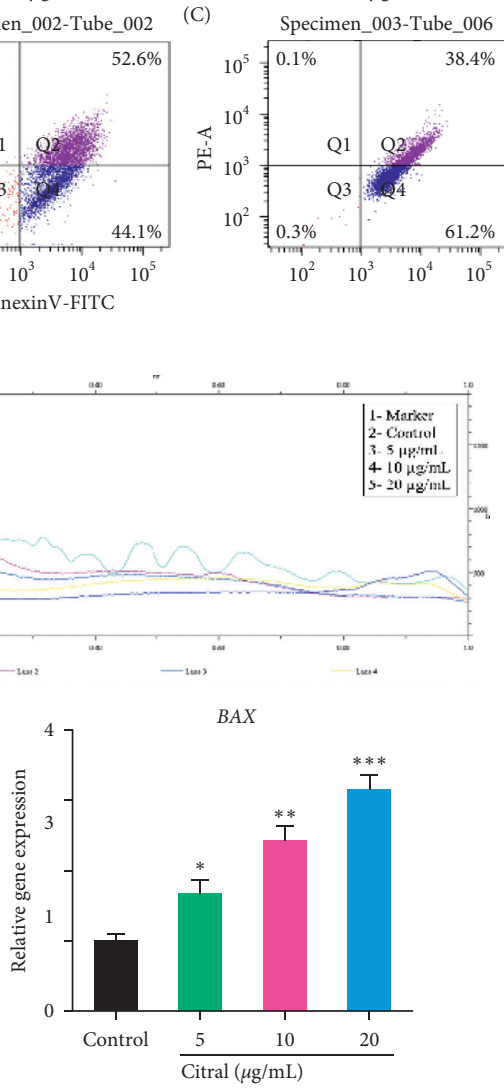

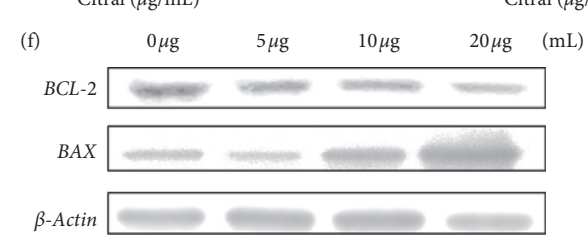

FIGURE 6: Citral induced apoptosis of prostate cancer cells. (a) Nuclear staining of prostate cancer cells with or without citral treatment using Hoechst dye. (b) Prostate cancer cells with or without treatment were stained with PI staining. The cells that remained intact does not allow cells to stain with the dye. However, the damage cells were stained with PI and indicated the apoptotic cells. (c) Flow cytometry analysis of cancer cells with or without treatment. Descriptive figures show the population of live cells (annexin V- PI-), early apoptotic (annexin $\mathrm{V}+\mathrm{PI}-$ ), late apoptotic cells (annexin V + PI+), and necrotic cells (annexin V-PI+). (d) DNA fragmentation analysis was carried out after the isolation of genomic DNA from prostate cancer cells with or without different concentrations of citral treatment. (e) The gene expression analysis of Bcl-2 and BAX was carried out in cells with or without citral treatment. Housekeeping gene $\beta$-actin was used as an internal control. (f) The Western blotting analysis performed using antibodies indicated in Section 2. Each bar represents the mean \pm standard error of triplicate samples from three independent experiments ( $p=0.05$, using Student's $t$-test). 


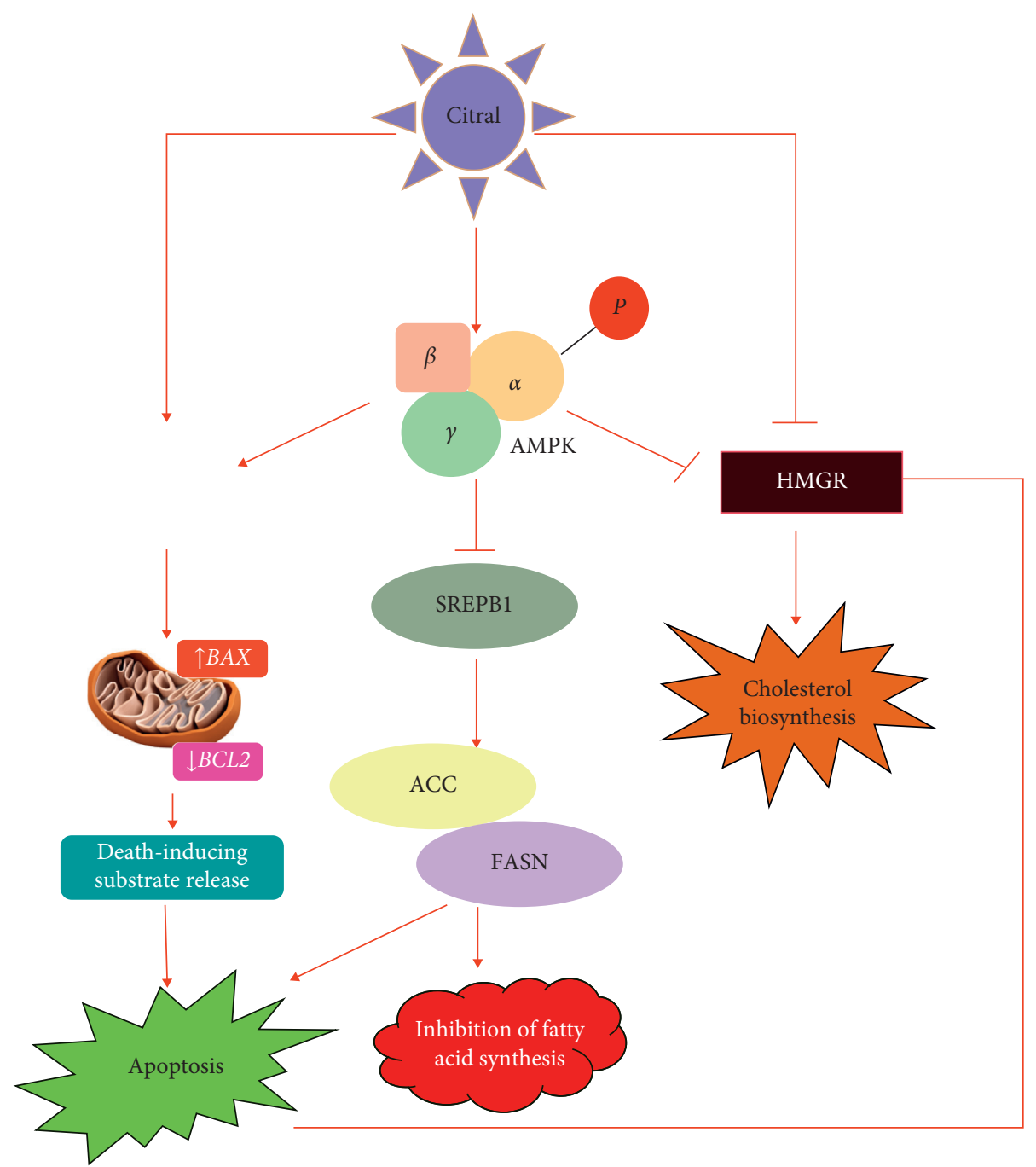

FIGURE 7: Tumor suppressing pathway of citral on prostate cancer cells. Upon citral treatment, the prostate cancer cell activates phosphorylation of AMPK and inhibits fatty acid synthesis and cholesterol pathway genes such as SREBP1, ACC, FASN, and HMGR and that in turn increases the expression of BAX, downregulates Bcl-2 expression, and promotes apoptosis.

\section{Conclusion}

We have isolated active ingredient citral from lemongrass oil and studied its anticancer properties against human prostate cancer cells. Typically, our results indicate that citral from lemongrass induces apoptosis driving lipogenesis pathway in both in silico and in vitro analyses. The citral suppressed colony formation, inhibited lipogenesis, and induced cell death through apoptosis. Induction of AMPK and downregulation of crucial genes involved in lipogenesis resulted in apoptosis exhibiting antiproliferative effects of citral (Figure 7). It is also noteworthy to suggest citral as a promising candidate as it absorbs well in the intestine and can exhibit its anticancer effects on prostate cancer cells. It will be interesting to investigate the in vivo action of citral against prostate cancer for the therapeutic use of citral as an anticancer drug.

\section{Abbreviations}

MTT: 3-(4,5-dimethylthiazol-2-yl)-2,5-diphenyl tetrazolium bromide
ADMET: Absorption, distribution, metabolism, excretion and toxicity

SREBP1: Sterol regulatory element-binding protein

FASN: Fatty acid synthase

BCL-2: B-cell lymphoma 2

BAX: Bcl-2-associated $\mathrm{X}$ protein

FBS: $\quad$ Fetal bovine serum

TLC: Thin-layer chromatography

RPMI: $\quad$ Roswell Park Memorial Institute

DMEM: Dulbecco's Modified Eagle's Medium

FBS: $\quad$ Fetal bovine serum

EDTA: Ethylenediaminetetraacetic acid

qRT- Quantitative real-time PCR

PCR:

PPB:

HIA: Human intestinal absorption

PASS: $\quad$ Prediction of activity spectra for substances

HRP: Horseradish peroxidase

CL: $\quad$ Confidence limits

$\mathrm{IC}_{50}$ : Inhibition concentration 
PS: $\quad$ Phosphatidylserine.

\section{Data Availability}

No data were used to support this study.

\section{Conflicts of Interest}

The authors have no conflicts of interest to declare.

\section{Authors' Contributions}

S. R. B. and H. P. designed the research, conceived the project, wrote the manuscript, performed the experiments, interpreted the results, and participated in the design of the study. K. V. and R. S. participated in the in silico study. Y. J. K. and M. A. H. helped in writing the manuscript. L. T. helped in the interpretation of results. Sri Renukadevi Balusamy and Haribalan Perumalsamy contributed equally to the manuscript.

\section{Acknowledgments}

This work was supported by the National Research Foundation grant (Grant no. 2019R1I1A1A01063845) and also supported by the Cooperative Research Program for Agriculture Science and Technology Development (Project no. PJ0128132017), Republic of Korea.

\section{Supplementary Materials}

Supplementary Figure S1: NMR spectrum of citral. (A) ${ }^{1} \mathrm{H}$ NMR. (B) 13832 C NMR spectra. (Supplementary Materials)

\section{References}

[1] D. M. Parkin, P. Pisani, and J. Ferlay, "Global cancer statistics," CA: A Cancer Journal for Clinicians, vol. 49, no. 1, pp. 33-64, 1999.

[2] H. G. Sim and C. W. S. Cheng, "Changing demography of prostate cancer in Asia," European Journal of Cancer, vol. 41, no. 6, pp. 834-845, 2005.

[3] C.-M. Oh, Y.-J. Won, K.-W. Jung et al., "Cancer statistics in korea: incidence, mortality, survival, and prevalence in 2013," Cancer Research and Treatment, vol. 48, no. 2, pp. 436-450, 2016.

[4] G. Joshi, P. K. Singh, A. Negi, A. Rana, S. Singh, and R. Kumar, "Growth factors mediated cell signalling in prostate cancer progression: implications in discovery of anti-prostate cancer agents," Chemico-Biological Interactions, vol. 240, pp. 120133, 2015.

[5] P. S. Ward and C. B. Thompson, "Metabolic reprogramming: a cancer hallmark even Warburg did not anticipate," Cancer Cell, vol. 21, no. 3, pp. 297-308, 2012.

[6] J. Suburu and Y. Q. Chen, "Lipids and prostate cancer," Prostaglandins \& Other Lipid Mediators, vol. 98, no. 1-2, pp. 1-10, 2012.

[7] J. Swierczynski, A. Hebanowska, and T. Sledzinski, "Role of abnormal lipid metabolism in development, progression, diagnosis and therapy of pancreatic cancer," World Journal of Gastroenterology, vol. 20, no. 9, pp. 2279-2303, 2014.
[8] N. J. Skill, R. E. Scott, J. Wu, and M. A. Maluccio, "Hepatocellular carcinoma associated lipid metabolism reprogramming," Journal of Surgical Research, vol. 169, no. 1, pp. 51-56, 2011.

[9] C. Nieva, M. Marro, N. Santana-Codina, S. Rao, D. Petrov, and A. Sierra, "The lipid phenotype of breast cancer cells characterized by Raman microspectroscopy: towards a stratification of malignancy," PLoS One, vol. 7, Article ID e46456, 2012.

[10] I. H. N. Bassolé, A. Lamien-Meda, B. Bayala et al., "Chemical composition and antimicrobial activity of Cymbopogon citratus and Cymbopogon giganteus essential oils alone and in combination," Phytomedicine, vol. 18, no. 12, pp. 1070-1074, 2011.

[11] G. Nonviho, V. D. Wotto, J. P. Noudogbessi, F. Avlessi, and M. Akogbeto, "Sohounhloué insecticidal activities of essential oils extracted from three species of poaceae on Anopheles gambiae spp, major vector of malaria," Scientific Study and Research, vol. 4, pp. 411-420, 2010.

[12] K. Ghosh, "Anticancer effect of lemon grass oil and citral on cervical cancer cell lines," Pharmacognosy Communications, vol. 3, no. 4, 2013.

[13] W. Chaouki, D. Y. Leger, B. Liagre, J.-L. Beneytout, and M. Hmamouchi, "Citral inhibits cell proliferation and induces apoptosis and cell cycle arrest in MCF-7 cells," Fundamental \& Clinical Pharmacology, vol. 23, no. 5, pp. 549-556, 2009.

[14] B. Bayala, I. H. N. Bassole, S. Maqdasy, S. Baron, J. Simpore, and J.-M. A. Lobaccaro, "Cymbopogon citratus and Cymbopogon giganteus essential oils have cytotoxic effects on cytotoxic tumour cell cultures. Identification of citral as a new putative anti-proliferative molecule," Biochimie, vol. 153, pp. 162-170, 2018.

[15] S. R. Balusamy, S. Ramani, S. Natarajan et al., "Integrated transcriptome and in vitro analysis revealed anti-proliferative effect of citral in human stomach cancer through apoptosis," Scientific Reports, vol. 9, no. 1, p. 4883, 2019.

[16] A. Daina, O. Michielin, and V. Zoete, "SwissADME: a free web tool to evaluate pharmacokinetics, drug-likeness and medicinal chemistry of small molecules," Scientific Reports, vol. 7, no. 1, p. 42717, 2017.

[17] S. K. Lee, I. H. Lee, H. J. Kim, G. S. Chang, J. E. Chung, and K. T. No, The preADME Approach: Web-Based Program for Rapid Prediction Processes, Problems, and Solutions, Blackwell Publishing, Malden, MA, USA, 2003.

[18] V. V. Poroikov, D. A. Filimonov, W. D. Ihelenfeldt et al., "PASS biological activity spectrum predictions in the enhanced open NCI database browser," Journal of Chemical Information and Computer Scientists, vol. 43, no. 1, pp. 223-236, 2003.

[19] F. M. Siraj, S. Natarajan, Y. J. Kim, and D. Chun Yang, "In silicoscreening of ginsenoside Rh1 with PPAR $\gamma$ andin vitroanalysis on 3T3-L1 cell line," Molecular Simulation, vol. 41, no. 15, pp. 1219-1226, 2014.

[20] A. J. Souers, J. D. Leverson, E. R. Boghaert et al., “ABT-199, a potent and selective BCL-2 inhibitor, achieves antitumor activity while sparing platelets," Nature Medicine, vol. 19, no. 2, pp. 202-208, 2013.

[21] C. W. Pemble, L. C. Johnson, S. J. Kridel, and W. T. Lowther, "Crystal structure of the thioesterase domain of human fatty acid synthase inhibited by orlistat," Nature Structural \& Molecular Biology, vol. 14, no. 8, pp. 704-709, 2007.

[22] A. Shamas-Din, J. Kale, L. Brian, and D. W. Andrews, "Mechanisms of action of Bcl-2 family proteins," Cold Spring Harbor Perspectives in Biology, vol. 5, no. 4, p. a008714, 2003. 
[23] O. Trott and A. J. Olson, "Autodock vina: improving the speed and accuracy of docking with a new scoring function, efficient optimization and multithreading," Journal of Computational Chemistry, vol. 31, no. 2, pp. 455-461, 2010.

[24] K. Veerappan, S. Natarajan, P. Ethiraj, U. Vetrivel, and S. Samuel, "Inhibition of IKK $\beta$ by celastrol and its analogues-anin silicoandin vitroapproach," Pharmaceutical Biology, vol. 55, no. 1, pp. 368-373, 2017.

[25] S. R. Balusamy, H. Perumalsamy, M. A. Huq, and B. Balasubramanian, "Anti-proliferative activity of Origanum vulgare inhibited lipogenesis and induced mitochondrial mediated apoptosis in human stomach cancer cell lines," Biomed \& Pharmcother, vol. 108, pp. 1835-1844, 2019.

[26] Perumalsamy, H Sankarapandian, K. Kandaswamy, N. Karpagam, V. Balusamy et al., "In silico and in vitro analysis of coumarin derivative induced anticancer effects by undergoing intrinsic pathway mediated apoptosis in human stomach cancer," Phytomed, vol. 92, no. 15, pp. 104-114, 2018.

[27] M. J. Zelefsky, J. A. eastham, A. M. Cronin et al., "Metastasis after radical prostatectomy or external beam radiotherapy for patients with clinically localized prostate cancer: a comparison of clinical cohorts adjusted for case mix," Journal of Clinical Oncology, vol. 28, no. 9, pp. 1508-1513, 2010.

[28] C. Brami, T. Bao, and G. Deng, "Natural products and complementary therapies for chemotherapy-induced peripheral neuropathy: a systematic review," Critical Reviews in Oncology/Hematology, vol. 98, pp. 325-334, 2016.

[29] S. E. Nigjeh, S. K. Yeap, N. Nordin, B. Kamalideghan, H. Ky, and R. Rosli, "Citral induced apoptosis in MDA-MB-231 spheroid cells," BMC Complementary and Alternative Medicine, vol. 18, no. 1, p. 56, 2018.

[30] T. M. A. Kitanaka, Y. Kubota, G. Yamaoka, T. Kameda et al., "Lemongrass essential oil and citral inhibit Scr/Stat3 activity and suppress the proliferation/survival of small-cell lung cancer cells, alone or in combination with chemotherapeutic agents," International Journal of Oncology, vol. 52, pp. 1738-1748, 2018.

[31] B. Y. Sheikh, M. M. R. Sarker, M. N. A. Kamarudin, and G. Mohan, "Antiproliferative and apoptosis inducing effects of citral via p53 and ROS-induced mitochondrial-mediated apoptosis in human colorectal HCT116 and HT29 cell lines," Biomedicine \& Pharmacotherapy, vol. 96, pp. 834-846, 2017.

[32] H. M. G. Vander, "Targeting cancer metabolism: a therapeutic window opens," Nature Reviews of Drug Discovery, vol. 10, no. 9, pp. 671-684, 2011.

[33] D. Hanahan and R. A. Weinberg, "Hallmarks of cancer: the next generation," Cell, vol. 144, no. 5, pp. 646-674, 2011.

[34] G. Zadra, C. Photopoulos, and M. Loda, "The fat side of prostate cancer," Biochim Biophys Acta, vol. 1831, no. 10, pp. 1518-1532, 2013.

[35] Z. Luo, A. K. Saha, X. Xiang, and N. B. Ruderman, "AMPK, the metabolic syndrome and cancer," Trends in Pharmacological Sciences, vol. 26, no. 2, pp. 69-76, 2005.

[36] Y. C. Long and J. R. Zierath, "AMP-activated protein kinase signaling in metabolic regulation," Journal of Clinical Investigation, vol. 116, no. 7, pp. 1776-1783, 2006.

[37] J. A. Menendez and R. Lupu, "Fatty acid synthase and the lipogenic phenotype in cancer pathogenesis," Nature Reviews Cancer, vol. 7, no. 10, pp. 763-777, 2007.

[38] M. Maria and S. J. Reuben, "The AMP-activated protein kinase (AMPK) signaling pathway coordinates cell growth, autophagy, \& metabolism," Nature Cell Biology, vol. 13, no. 9, pp. 1016-1023, 2011.

[39] L. H. Young, "A crystallized view of AMPK activation," Cell Metabolism, vol. 10, no. 1, pp. 5-6, 2009. 